\title{
Teaching Careers: Exploring Links Between Well-Being, Burnout, Self-Efficacy and Praxis Shock
}

\author{
Julie Ballantyne* and James Retell \\ The University of Queensland, Brisbane, QLD, Australia
}

Burnout and attrition are issues facing many professions. In a bid to better understand this phenomenon and ways to address it, this paper explores experiences of praxis shock, well-being, burnout, and self-efficacy during teachers' careers. Regression and mediation analyses of 836 responses to a questionnaire reveal that praxis shock may occur at multiple points in a music teachers' career. Findings reveal that praxis shock predicts patterns of reported burnout, well-being and self-efficacy. This impacts on the development of productive professional identities, career satisfaction and success. Evidence is presented regarding praxis shock and its impact across a teaching career.

OPEN ACCESS

Edited by: Caterina Fiorilli,

LUMSA University, Italy

Reviewed by:

llaria Buonomo,

LUMSA University, Italy Maria Popa-Roch,

Université de Strasbourg, France

*Correspondence: Julie Ballantyne j.ballantyne@uq.edu.au

Specialty section: This article was submitted to Organizational Psychology, a section of the journal Frontiers in Psychology

Received: 16 May 2019 Accepted: 20 September 2019 Published: 18 February 2020

Citation:

Ballantyne J and Retell J (2020) Teaching Careers: Exploring Links Between Well-Being, Burnout, Self-Efficacy and Praxis Shock.

Front. Psychol. 10:2255. doi: 10.3389/fpsyg.2019.02255
Keywords: teacher education, music teacher attrition, professional identities, pre-service and in-service education and training, occupational stress

\section{INTRODUCTION}

Professional identities are the ways teachers make sense of themselves within their professional lives. They encompass and are interrelated with personal identities, social and cultural identities and norms, and professional roles and contexts. Research consistently notes the centrality of teachers' professional identities to all aspects of their job. Professional identities particularly impact on teachers' abilities to navigate the complexities of 'being a teacher' (Beijaard et al., 2004; Sachs, 2005). This is because the notion of 'who I am as a teacher' influences, and is influenced by, self-perceptions of agency, self-efficacy, effectiveness, and job satisfaction (Day and Kington, 2008; Skaalvik and Skaalvik, 2014). Although many inroads have been made into researching professional identities and the experiences of beginning teachers (see for example Flores and Day, 2006; Beauchamp and Thomas, 2009; Hong, 2010; Pillen et al., 2013), there is still a need to better understand how teachers traverse through other career periods. This article explores how the components of perceived professional identity (including praxis shock, burnout, well-being, and self-efficacy) interact across the teaching career.

Research on the career and identities intersect where both fields acknowledge that broader issues in a person's job and life are relevant when exploring changes over time (Day and Gu, 2007). As people progress through their chosen profession, their experiences and the ways that they respond to all aspects of their work, change and develop. Research suggests that career development is seen as a "whole-life" endeavor, necessarily encompassing the myriad facets of a person's life that may impact on their career (Litano and Major, 2016). Individuals who are in the profession of teaching are therefore expected to experience changes that will influence their career, over time.

Gu and Day (2007) emphasize that teachers' abilities to "cope" in their professional lives are impacted by their identities and professional life phases, which are in turn mediated by issues in their personal and situated lives, their professional values, beliefs, and external policy agendas. The 
"ability to cope", or remain resilient in the face of considerable job uncertainty, job stress, policy changes and career challenges, appears to be most challenging to teachers at the beginning of their careers, when they tend to burn out and leave the profession (Schaefer, 2013). Teachers' responses to career changes and stress vary, but it does seem that teachers are leaving the profession because they are "burning out" (Parliament of Australia Media Release, 2019). As indicated by its name, "burning out" is often the end point of a negative response to work stress and emotional exhaustion (Skaalvik and Skaalvik, 2007). Burnout (and attrition) is affecting the profession (perhaps across the career span), and this is of grave concern to policy-makers, teacher education providers, employers and government bodies alike.

Research on attrition and burnout in teaching necessarily reflects the highly complex and multi-faceted experience of teachers in the workforce (Lindqvist et al., 2014). Burnout has been associated with mental and physical health (Hultell et al., 2013), as well as work environment and motivational factors (Fernet et al., 2012). It can also be attributed to 'clients' or students (Kristensen et al., 2005). Thus, when investigating teacher professional identities, measuring burnout provides a picture of the degree to which teachers feel fatigued as a direct result of their work, and therefore the likelihood of their remaining a teacher. Interestingly, recent work by Hultell et al. (2013), suggests that burnout might not exclusively be the domain of the early career teacher, finding that during their first 3 years of employment, teachers were, on average, relatively healthy with moderately low, albeit increasing, levels of burnout (p. 84).

The day-to-day life of a school teacher often represents a fundamental divergence from the expectations and ideals that are held prior to entering the profession. The feeling of surprise, shock or disequilibrium resulting from this experience has been termed praxis shock and is most common in the early years of teaching (Kelchtermans and Ballet, 2002; Stokking et al., 2003; Ballantyne, 2007). The mismatch experienced when one's expectations of professional life do not align with the realities experienced working within the profession, is likely to be accompanied by a sense of disillusionment and disappointment. Managing praxis shock compounds the burden faced by early career professionals and those who experience praxis shock are likely to be less effective in their work, and may be unable to provide their schools and communities with the best possible provision of education. The experience of praxis shock can result in burnout (Ballantyne, 2007), and is also associated with attrition and reduced job satisfaction (Kelchtermans and Ballet, 2002; Ballantyne, 2005, 2007; Hong, 2010; Skaalvik and Skaalvik, 2010). Burnout can also be reduced or mitigated against "when teachers have a positive perception of their self-efficacy" (Betoret, 2006, p. 534). Arguably, the ways that teachers perceive praxis shock actually may be the key to successful identity development, and longevity in the career (Ballantyne and Zhukov, 2017).

Burnout, praxis shock and attrition are clearly interrelated areas of study examined by researchers in the fields of teacher education and teacher education (Kelchtermans and Ballet, 2002; Ballantyne, 2005, 2007; Hong, 2010; Skaalvik and Skaalvik, 2010). Burnout, praxis shock and attrition are also related to issues of job satisfaction and self-efficacy (Skaalvik and Skaalvik, 2010).
Perceived self-efficacy is aligned with success in the profession, with Bandura (2006) maintaining that "the stronger the perceived self-efficacy, the higher the performance attainments" (p. 175). For the purposes of this study, the definition of self-efficacy was borrowed from Skaalvik and Skaalvik (2014), in that it refers to teachers' beliefs about their own abilities to plan, organize, and carry out activities required to attain education goals" (p. 69). Skaalvik and Skaalvik found that better self-efficacy increased job satisfaction, and conversely, poor self-efficacy increased the likelihood of burnout in the profession. Previous research in this area links self-efficacy and psychological well-being, personal accomplishment, job satisfaction, and commitment (Zee and Koomen, 2016). Self-efficacy is strongly associated with images of self, and Beijaard et al. argue that such images "strongly determine the way teachers teach, the way they develop as teachers, and their attitudes toward educational changes" (2004, p. 108). It is important, therefore, when examining teacher professional identities over the career, to also investigate teacher self-efficacy.

Most studies in this area focus on the experiences of beginning teachers (Kelchtermans and Ballet, 2002, Kelchtermans and Ballet, 2002; Ballantyne, 2007; Hong, 2010; Shaw, 2016), and very little research has investigated how teacher efficacy, burnout and teacher identity intersect in the lives of teachers across their careers. In addition, no work has approached the experiences of teachers using praxis shock as a way to investigate the interrelationships that might exist between self-efficacy, wellbeing and burnout.

This study examined the perceptions of music teachers specifically, as it has been consistently argued that the experiences of early career music teachers are characterized by practical challenges associated with teaching the discipline area (Krueger, 2001; Scheib, 2006; Ballantyne, 2007; Conway, 2012; Legette, 2013). This is implicated in the findings by Buonomo et al. (2017), who argue that the contextual stressors provided by teaching roles which require extracurricular responsibilities and workload (like music teachers) are at greater risk of burnout. Much has also been made of the particular nature of music teacher professional identity, whereby performing music (or seeing oneself as a musician), is central to the conception of success as a teacher (Mark, 1998; Ballantyne, 2005, 2007; Ballantyne and Grootenboer, 2012; Ballantyne et al., 2012; Ballantyne and Zhukov, 2017). This work thus extends previous work into the development of productive music teacher identities in pre-service in-service music teachers (Ballantyne, 2007; Ballantyne et al., 2009, 2012; Ballantyne and Zhukov, 2017).

This article explores (1). how teachers' self-reported levels of burnout and self-efficacy, well-being and praxis shock vary as a function of time in the profession, and (2). the effect of praxis shock and the extent to which it can influence the reported experiences of burnout, well-being and self-efficacy in practicing music teachers. Information was gathered around the nature of music teachers' experiences across the career span, so as to explore variation in these experiences at different career stages. Specifically, we predicted that reports of praxis shock and burnout would be more common in earlier career 
teachers and decrease across the career span, while wellbeing and self-efficacy would have the opposite relationship. Investigating the relationships between these factors create improved understandings around the experiences of music teachers throughout their career. The findings of this paper thus may be used to inform support mechanisms for teachers who may be experiencing difficulties in their jobs, and are at risk of 'burning out (Day and Gu, 2007).

\section{MATERIALS AND METHODS}

A questionnaire was designed to explore the experiences of music teachers as they progressed through their career.

\section{Development of the Questionnaire and Conceptual Frame}

The questionnaire comprised scales investigating music teacher self-efficacy and socialization into the profession, specifically looking at praxis shock, well-being, burnout and self-efficacy and how they change over time.

\section{Praxis Shock}

Measuring the experience of praxis shock provides a primary contribution to previous research in this field. The subscale, developed for the purpose of this study, was based on a review of prior theoretical work (Mark, 1998) and qualitative work (Kelchtermans and Ballet, 2002; Ballantyne, 2007) where praxis shock was associated with early-career teachers' surprise or shock in relation to aspects of socialisation, workload, isolation, induction and relationships with students and staff. We considered praxis shock to be the feeling of surprise, shock or disequilibrium that results from a discrepancy between an expectation of a workplace environment and what it should be like, and the reality which may be somewhat different. The questions relating specifically to praxis shock measured 1 . the degree of shock or surprise associated with these different components of teaching life, and 2. the degree to which there was dissonance between expectations of teaching life and reality experienced (see Appendix A).

\section{Burnout}

Burnout was examined using items from the Copenhagen Burnout Inventory (CBI) (Kristensen et al., 2005) which defines this construct as "a state of physical, emotional, and mental exhaustion that results from long-term involvement in work situations that are emotionally demanding" (2005, p. 196). The current questionnaire incorporated the $\mathrm{CBI}$ items measuring work-related and client-related burnout. CBI items relating to a third domain - personal burnout - were omitted due to redundancy with other questionnaire items. It is notable that the CBI was originally designed to be applicable across a range of work contexts: the "work" in this instance is teaching, and the "clients" are the students. Work-related burnout is defined as the "degree of physical and psychological fatigue and exhaustion that is perceived by the person as related to his/her work", while client (student)-related burnout is defined as the "degree of physical and psychological fatigue and exhaustion that is perceived by the person as related to his/her work with clients" (Kristensen et al., 2005, p. 197). Importantly, the items are intended to measure a direct attribution of work or clients to one's state of fatigue, and not another external factor.

Items measuring work-related burnout were divided into two parts. The first three questions related to intensity of burnout (specifically in relation to teaching) and were measured on a 5point Likert scale. The final four questions probed the frequency of work burnout on a 5-point Likert scale (see Appendix A). The student-related burnout included items explored the extent to which students contributed to teachers' burnout, and the frequency of the student-related burnout. These were also ranked on a 5-point scale. The full complement of questions referred to in this paper (including division into student-related burnout and work-related burnout) are found in Appendix A.

\section{Well-Being}

The questionnaire utilized the World Health Organisation-Five Well-Being Index (1998) version). All items included in this five-item scale are positively worded and designed to measure psychological well-being through such dimensions as mood, vitality and general interest in life ${ }^{1}$ (see Appendix A). It is scored on a 6-point scale, which was reversed for this questionnaire to reflect the same order as the scales in the other questions. The six points range from 0 - At no time, to 5 - All of the time.

\section{Self-Efficacy}

Self-efficacy was investigated as it related to teaching activities. Teaching self-efficacy is also related to the individual teacher's estimation of their resilience to changes in circumstances and context. This component of the questionnaire was drawn from the Music Careers Questionnaire II (Hargreaves et al., 2007), although a 6-point Likert scale (strongly disagree to strongly agree) has been utilized. The wording of these items was specifically phrased "in terms of can do rather than will do", to tap "perceived capability" in accordance with Bandura's guidelines (2006, p. 308). The 17 statements covered elements of teaching practice such as lesson planning (e.g., "When I plan lessons, I am certain I can make them work"), perseverance (e.g., "If a lesson goes poorly the first time, I try again until it works better"), avoidance (e.g., "I avoid facing difficult situations in my teaching"), determination (e.g., "When I decide to do something, I go right to work on it") and confidence (e.g., "I feel insecure about my teaching; I am a self-reliant teacher").

Tschannen-Moran and Woolfolk-Hoy (2001) argue that teachers with greater self-efficacy are more able to cope with change. Thus, self-efficacy was also investigated in terms of respondent's self-reported ability to "cope with change" and respondents rated confidence in their capacity to demonstrate a range of skills and behaviors relating to coping with change in schooling environments. This component of the questionnaire borrowed from a bank of questions developed by Skaalvik and Skaalvik (2010) in their investigation of teacher self-efficacy and teacher burnout, and is designed to investigate how "certain"

\footnotetext{
${ }^{1}$ http://www.who-5.org
} 
TABLE 1 | Reliability of measures.

\begin{tabular}{lcc}
\hline Measure & Cronbach's alpha & Number of items \\
\hline Praxis shock & 0.886 & 15 \\
Self-efficacy & 0.845 & 17 \\
Self-efficacy: CwC & 0.868 & 4 \\
Work-related burnout & 0.883 & 7 \\
Student-related burnout & 0.841 & 6 \\
Well-being & 0.870 & 5 \\
\hline
\end{tabular}

participants were about various aspects of teaching. A 7-point Likert scale was used with modification (Skaalvik and Skaalvik did not specify descriptors for 2, 4 and 6 in the Likert scale, so for the purpose of this study, the complete range of descriptors was assumed): 1- Not at all certain, 2 - Very uncertain, 3 - Quite uncertain, 4 - Neither certain or uncertain, 5 - Quite certain, 6 Very certain, 7 - Absolutely certain. The categories have been used as they were in the original, and are from the cluster of questions related to coping with change. They are: "successfully use any instructional method that the school decides to use"; "manage instruction regardless of how it is organized"; "manage instruction even if the curriculum is changed", and; "teach well even if you are told to use instructional methods that would not be your choice". Again, the "can" and "I" wording utilized is reflective of the guides suggested by Bandura (2006). The full complement of questions referred to in this paper (including division into self-efficacy and self-efficacy: cope with change) are found in Appendix A.

\section{Reliability}

The reliability of all measures was assessed using Cronbach's alpha. All measures had a reliability greater than 0.8 (see Table 1).

\section{Participants and Procedure}

In order to address the research questions, an online questionnaire was distributed to music teachers via an online community of practice, advertisements in professional list-serves, social media, and professional associations. This questionnaire was sent out over 3 years, in 2012, 2013, and 2014 .

A total of 1021 respondents attempted the questionnaire with 836 people completing at least $50 \%$ of the questionnaire. Participants who completed less than $50 \%$ of the questionnaire were removed from all analyses. Because of the ethics requirements associated with voluntary participation in online questionnaires, if someone chose not to answer a question, they were excluded from the analyses that utilize that item. This explains the varied number of responses in each item of the analyses presented.

As Table 2 shows, $81 \%$ of respondents were female, with $19 \%$ male. The vast majority of respondents (85\%) came from Australia, with additional respondents from the United States (9\%) and other countries (6.2\%). Of the Australian respondents, the majority came from Queensland (45\%), followed by New South Wales (20\%), Western Australia (16\%), and Victoria (11\%). The sample had a large number of younger (under 25) and older (51-60) respondents (25\% in each instance), with the remaining
$50 \%$ of respondents aged $26-50.63 \%$ of respondents taught at one school, and $20 \%$ taught at two schools, with the majority teaching at State Schools (55\%), and 29\% teaching at Christian or Catholic Schools. 31\% of respondents had completed some sort of dual degree in Music or Arts and Education. 20\% had completed straight degrees in Education. 26.2\% had completed a Bachelor of Music, and 22.9 had completed a Graduate Diploma of Education. $36.8 \%$ had completed another (unnamed) degree.

\section{Missing Data}

The data is not as precise for the latter period of the career. In the initial iteration of the questionnaire (2012), respondents who selected "more than 20 years teaching" were given a code of " 21 " for "years of teaching". In subsequent iterations (2013 and 2014), additional questions associated with how long they had been teaching, in which year they began teaching and the year of their graduation from university. For analysis purposes, cases of yearsteaching greater than 21 were reclassified as 21 years-teaching. That is, 21 years was the upper limit on the years teaching scale.

\section{RESULTS AND DISCUSSION}

\section{How Teachers' Self-Reported Levels of Burnout and Self-Efficacy, Well-Being and Praxis Shock Vary Over Time in the Profession}

Regression analyses were used to evaluate the degree to which the constructs of interest (e.g., praxis shock, self-efficacy, wellbeing, and burnout) varied as a function of time spent teaching in years. Participants' means score on each measure were used in the regression analyses. All analyses were run using Stata (15) software.

Linear regression analyses revealed significant $(p<0.05)$ linear relationships between years teaching and all the outcome variables except for self-efficacy: cope with change. Consistent with our predictions, self-efficacy and well-being were positively related to years teaching, while work-related burnout, studentrelated burnout, and praxis shock were negatively related to years teaching (see Table 3 ). Figure 1 provides graphical representations of the linear models described here. Regarding the assumptions of the linear models, in all cases, the error variance was constant as a function of years teaching. That is, the assumption of homoscedasticity was met. Normality was assessed using quantile-quantile plots (see Figure 2). Both selfefficacy: cope with change and student-related burnout show some divergence from normality, though only in the tails. Neither a natural log or square root transformation could correct this. Otherwise, the model residuals appear normally distributed.

Early career respondents in our sample tended to report increased levels of praxis shock which declined steadily with time spent within the profession. However, it is important to note that this linear decline was small, and it is clear that praxis shock remained an issue beyond the early years in the profession. Indeed, there are clear cases of respondents who have taught for 21 years or more experiencing high levels of praxis shock. This is 
TABLE 2 | Demographic information of respondents.

\begin{tabular}{|c|c|c|c|c|c|c|c|c|c|c|}
\hline $\begin{array}{l}\text { Years teaching } 1 \\
n=702\end{array}$ & $\mathrm{Age}^{2} n=665$ & Gender $n=675$ & $\begin{array}{l}\text { School type } \\
n=632\end{array}$ & Country $n=666$ & $\begin{array}{l}\text { For Australian } \\
\text { Respondents, } \\
\text { State } n=477\end{array}$ & $\begin{array}{l}\text { At how many } \\
\text { schools do you } \\
\text { teach? } n=456\end{array}$ & $\begin{array}{l}\text { Course } \\
\text { completed } \\
n=1063^{*}\end{array}$ & & $\begin{array}{l}\text { Type of teacher } \\
n=1328^{*}\end{array}$ & \\
\hline $0-1$ years $=14.7 \%$ & $<26=25 \%$ & Male $19 \%$ & $\begin{array}{l}\text { Independent, } \\
\text { non-Christian } \\
\text { school =6.7\% }\end{array}$ & Australia $=85.1$ & $\mathrm{ACT}=3.4 \%$ & $1=62.7 \%$ & $\begin{array}{l}\text { Bachelor of } \\
\text { Music/Bachelor of } \\
\text { Education }\end{array}$ & $24.1 \%$ & & \\
\hline $2-3$ years $=3.7 \%$ & $26-30=14.9 \%$ & Female $81 \%$ & $\begin{array}{l}\text { State } \\
\text { School }=55.1 \%\end{array}$ & United States $=8.7 \%$ & NSW = 20.3\% & $2=19.5 \%$ & $\begin{array}{l}\text { Bachelor of } \\
\text { Arts/Bachelor of } \\
\text { Education }\end{array}$ & $6.9 \%$ & $\begin{array}{l}\text { Secondary school } \\
\text { classroom music } \\
\text { teacher }\end{array}$ & $36.8 \%$ \\
\hline $4-5$ years $=10.3 \%$ & $31-40=18.3 \%$ & & $\begin{array}{l}\text { Catholic } \\
\text { School = 12.8\% }\end{array}$ & Other $=6.2$ & $\mathrm{NT}=0.6 \%$ & $3=7.9 \%$ & $\begin{array}{l}\text { Bachelor of } \\
\text { Education } \\
\text { (Secondary) }\end{array}$ & $5.9 \%$ & $\begin{array}{l}\text { Primary school } \\
\text { classroom music } \\
\text { teacher }\end{array}$ & $48.1 \%$ \\
\hline $6-10$ years $=14.4 \%$ & $41-50=19.6 \%$ & & $\begin{array}{l}\text { Church/Christian } \\
\text { School (other than } \\
\text { Catholic) }=13.8 \%\end{array}$ & & $\mathrm{QLD}=45.3$ & $4=2.6 \%$ & $\begin{array}{l}\text { Bachelor of } \\
\text { Education (Primary) }\end{array}$ & $14.1 \%$ & $\begin{array}{l}\text { Instrumental music } \\
\text { teacher } \\
\text { (Secondary) }\end{array}$ & $33.6 \%$ \\
\hline $11-15$ years $=10.0 \%$ & $51-60=24.5 \%$ & & Other $=11.7 \%$ & & $\mathrm{SA}=2.3 \%$ & $5=3.7 \%$ & Bachelor of Music & $26.2 \%$ & $\begin{array}{l}\text { Instrumental music } \\
\text { teacher (Primary) }\end{array}$ & $24.3 \%$ \\
\hline $16-20$ years $=10.1 \%$ & & & & & $\mathrm{TAS}=1.7 \%$ & $6=1.5 \%$ & Bachelor of Arts & $11.3 \%$ & $\begin{array}{l}\text { Studio music } \\
\text { teacher }\end{array}$ & $39.7 \%$ \\
\hline \multirow[t]{4}{*}{$\begin{array}{l}\text { More than } 20 \text { years } \\
\text { teaching }=36.9 \%\end{array}$} & & & & & $\mathrm{VIC}=10.7 \%$ & 7 or more $=2 \%$ & $\begin{array}{l}\text { Graduate Diploma } \\
\text { of Education }\end{array}$ & $22.9 \%$ & $\begin{array}{l}\text { Other (please } \\
\text { describe) }\end{array}$ & $15.2 \%$ \\
\hline & & & & & $W A=15.7 \%$ & & $\begin{array}{l}\text { Graduate Diploma } \\
\text { of Music }\end{array}$ & $6.5 \%$ & & \\
\hline & & & & & & & Master of Teaching & $5.3 \%$ & & \\
\hline & & & & & & & $\begin{array}{l}\text { Other (please list as } \\
\text { many as required) }\end{array}$ & $36.8 \%$ & & \\
\hline
\end{tabular}

*Values exceed the total sample size as respondents could provide multiple responses to many of these questions. ${ }^{1}$ It should be noted that responses were coded at '21' years of teaching when respondents selected 'more than 20 years teaching' in the first year of the questionnaire (2012). Although the questionnaire was initially designed for early-career teachers, when it became apparent that this questionnaire was applicable and interesting to more experienced teachers, subsequent iterations asked respondents a series of questions related to years in the profession, to more accurately assess their number of years teaching. Respondents were asked how long they had been teaching, in which year they began teaching, and the year of their graduation from university. In some cases, respondent's age did not match with the number of years that they said they had been teaching, and the years since they graduated university. This is because of the prevalence of private tuition as a source of income during university for music students. However, for the purposes of this they had been teaching, and the years since they graduated university. This is because of the prevalence of private tuition as a source of income during university for music students. However, for the purposes of this
study, we considered the number of years teaching to be the number of years teaching since graduation, and therefore adjusted the number of years teaching variable to reflect this. ${ }^{2}$ When the data from 2012 was being cleaned, there was the need to assign an actual value for those who were outside of the range option provided for 'age.' It was deemed important to include those people in the sample (those who had provided an age of 'less than 20 years,' and those who had provided an age of 'more than 50 years'), and they were given a nominal age of '19' and '51' respectively. Those respondents who chose not to reveal their age were removed from the 'age' sample. This is standard practice in the cleaning of data. This ensured that the merging of the data from 2012, 2013 and 2014 was consistent. 
TABLE 3 | Change in psychological outcomes as a function of years teaching.

\begin{tabular}{lcccc}
\hline DV & Linear $\mathbf{R}^{\mathbf{2}}$ (adjusted) & $\boldsymbol{\beta}$ & $\boldsymbol{F}$ & $\boldsymbol{p}$ \\
\hline Self-efficacy & $0.036(0.035)$ & 0.014 & 28.73 & $<0.001$ \\
Self-efficacy: CWC & $0.016(0.003)$ & 0.005 & 1.20 & 0.274 \\
Well-being & $0.026(0.025)$ & 0.019 & 19.11 & $<0.001$ \\
Work-related burnout & $0.018(0.017)$ & -0.013 & 13.54 & $<0.001$ \\
Student-related burnout & $0.010(0.009)$ & -0.009 & 8.03 & 0.006 \\
Praxis shock & $0.015(0.014)$ & -0.011 & 10.82 & 0.001 \\
\hline
\end{tabular}

an interesting phenomenon that was not anticipated in this study and is not previously documented. Persistence of praxis shock may be evident for a number of reasons, but is likely to reflect the fact that praxis shock can emerge when there is a discrepancy between the expectation of teaching life, and the realities faced by teachers. That this was a reality for experienced teachers as well as early career teachers, was unexpected. Praxis shock amongst experienced teachers may reflect the distance between the changing philosophies and expectations held by statutory bodies and management, and which teachers are expected to embody. Or perhaps music teachers commonly find themselves in new (more senior) roles and with new duties, irrespective of teaching experience. Any dissonance between their perceived skill set and the skills required may prompt praxis shock and burnout. Indeed, the praxis shock observed in this data set may be related to recent changes in terms of requirements, and the changes in relation to "what teaching is all about" in many schools. The current data do not shed light on this, but certainly provides the impetus for further investigation and at best may indicate an unexpected need for support for this demographic of the profession.

In summary, the series of linear regressions reported above show that teachers' self-reported levels of burnout, self-efficacy, well-being, and praxis shock vary over their time in the teaching profession. More specifically, we found that self-efficacy and well-being showed a small steady increase with the number of years teaching. While praxis shock, work, and student-related burnout behaved in the opposite manner, where both decreased slightly with number of years teaching.

\section{How the Constructs of Well-Being, Burnout and Self-Efficacy Relate to Teachers' Experiences of Praxis Shock}

The similarities observed between the linear models above suggest that there may be some degree of interrelationship between praxis shock and the other psychological constructs. The working hypothesis was that experience with praxis shock may account for differences in well-being, student- and workburnout and self-efficacy across the teaching career. While it has been argued that the experience of praxis shock can result in burnout (Ballantyne, 2007; Ballantyne and Zhukov, 2017), and is also associated with attrition and reduced job satisfaction (Kelchtermans and Ballet, 2002; Ballantyne, 2005, 2007; Hong, 2010; Skaalvik and Skaalvik, 2010), existing literature is restricted to qualitative documentation of the existence of praxis shock in teachers (Stokking et al., 2003; Smagorinsky et al., 2004; Ballantyne, 2007), indicating that it might be linked to well-being, student- and work-related burnout, and selfefficacy. As such, we ran a series of mediation analyses to test whether praxis shock might mediate the relationship between years of teaching and self-efficacy, well-being, and student- and work-related burnout.

\section{Mediation Analyses}

Mediation analyses were run to test whether the relationship between years in the profession and all other factors was mediated by praxis shock. In all cases, the relationship was significant (see Table 4), with praxis shock partially mediating the direction of the outcomes over time. The one exception was student-related burnout where we observed a full mediation of the relationship.

The mediation analyses provide moderate evidence that praxis shock is a contributing factor to the relationship between years teaching and our outcomes variables self-efficacy, wellbeing and work- and student-related burnout. That is, as the degree of praxis shock reduces as teachers stay in the profession, this reduction partially mediates the relationship between increased years of teaching experience, and the outcomes of burnout, self-efficacy, and well-being. Higher levels of praxis shock contribute to increased levels of burnout and decreased levels of well-being and self-efficacy and vice versa. In characterizing the degree of evidence as moderate, we are acknowledging that the mediation analyses are close to the significance threshold. Although scientific conclusions should not be based on whether $p$-values passes a specific threshold, future studies may seek to replicate these effects to confirm their reliability.

\section{Exploratory Analyses}

Finally, we ran one last set of exploratory analyses. It's clear from Figure 1 that a large amount of variance in the data is unaccounted for by the simple linear models. That is, the relationship between praxis shock and years teaching appears more nuanced than a simple linear one. Certainly, from a theoretical perspective, we might expect the relationships to vary between early- versus late-career teachers. Most of the previous literature has focussed on the existence of praxis shock in the early years of the profession, and in particular the experiences of early career music teachers (Ballantyne, 2007; Ballantyne and Zhukov, 2017). This is logically because it focusses on the discrepancies between university preparation and expectations prior to graduation, and the realities of teaching. To explore possible subtle differences in the relationships explored

TABLE 4 | Statistical output for the mediation tests investigating praxis shock as a mediator of the relationship between years teaching and significant outcomes.

\begin{tabular}{lcc}
\hline & Mediation $\boldsymbol{\beta}(\boldsymbol{p})$ & Bootstrap $\mathbf{C l}$ 95\% \\
\hline Well-being & $0.0033(0.049)$ & 0.0004 to 0.0061 \\
Self-efficacy & $0.0012(0.038)$ & 0.00004 to 0.0023 \\
Work-related burnout & $-0.0039(0.033)$ & -0.007 to -0.0005 \\
Student-related burnout & $-0.0026(0.025)$ & -0.005 to -0.003
\end{tabular}


above between the early and late career teacher cohorts, we split the data according to early career $(0-5$ years $)$ and more advanced career teachers ( $>5$ years). A series of Pearson's correlations between years teaching and our psychological constructs of interest were run for earlier $(\leq 5)$ and later career teachers $(>5)$. We stress that this set of correlation analyses are very much exploratory, run in response to the complex pattern of data observed above. The results are reported in Table 5.

The key result from Table $\mathbf{5}$ is that, in some cases, the relationship between years teaching and the respective psychological construct appears to differ as a function of early versus later career. Specifically, for well-being, work burnout, and praxis shock, the direction of the relationship for early and later career teachers is reversed. Well-being looks to decrease very slightly in the first 5 years of teaching and increase thereafter. The opposite is true for praxis shock and work burnout. No effect of self-efficacy or self-efficacy: cope with change was observed here. It appears that early-career teachers are most vulnerable to experiencing praxis shock and burnout. However, increased time (beyond $\sim 5$ years) in the profession may bring only a small reprieve from these experiences.
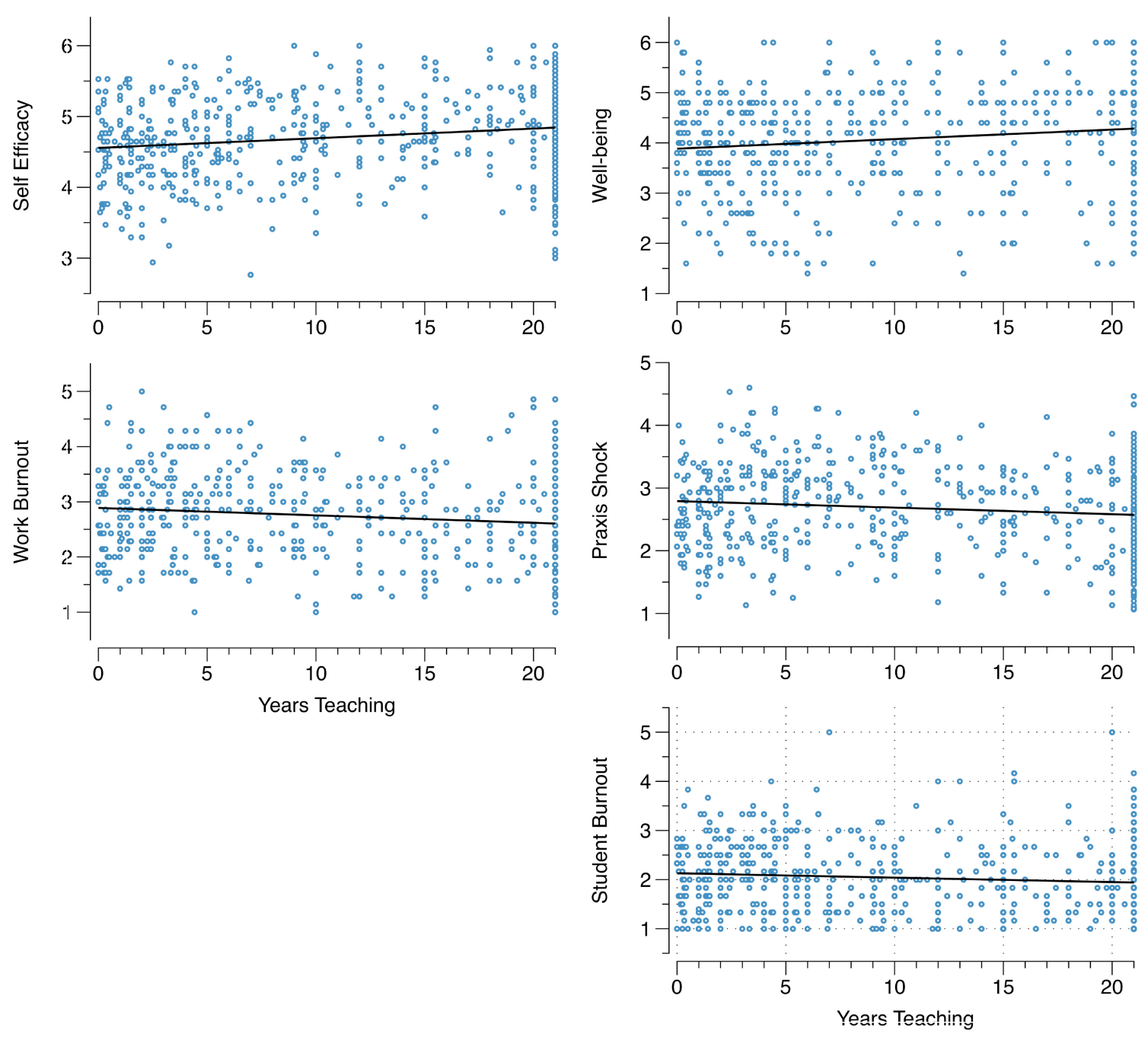

FIGURE 1 | Self-efficacy, well-being, work burnout, praxis shock, and student burnout as a function of years teaching, all with linear fits to the data.

TABLE 5 | Bivariate relationships between number of years teaching and all outcomes for early-career, mid-career, and late-career periods in the profession.

\begin{tabular}{|c|c|c|c|c|c|c|c|c|c|c|c|c|}
\hline & \multicolumn{2}{|c|}{ Well-being } & \multicolumn{2}{|c|}{ Self-efficacy } & \multicolumn{2}{|c|}{ Self-efficacy CWC } & \multicolumn{2}{|c|}{ Work burnout } & \multicolumn{2}{|c|}{ Student burnout } & \multicolumn{2}{|c|}{ Praxis shock } \\
\hline$<5$ year (early-career) & -0.175 & 0.013 & 0.080 & 0.259 & -0.024 & 0.732 & 0.165 & 0.020 & 0.145 & 0.041 & 0.184 & 0.010 \\
\hline 5-21 year (mid-career) & 0.141 & 0.001 & 0.050 & 0.239 & -0.042 & 0.328 & -0.117 & 0.007 & -0.065 & 0.144 & -0.222 & $<0.001$ \\
\hline
\end{tabular}



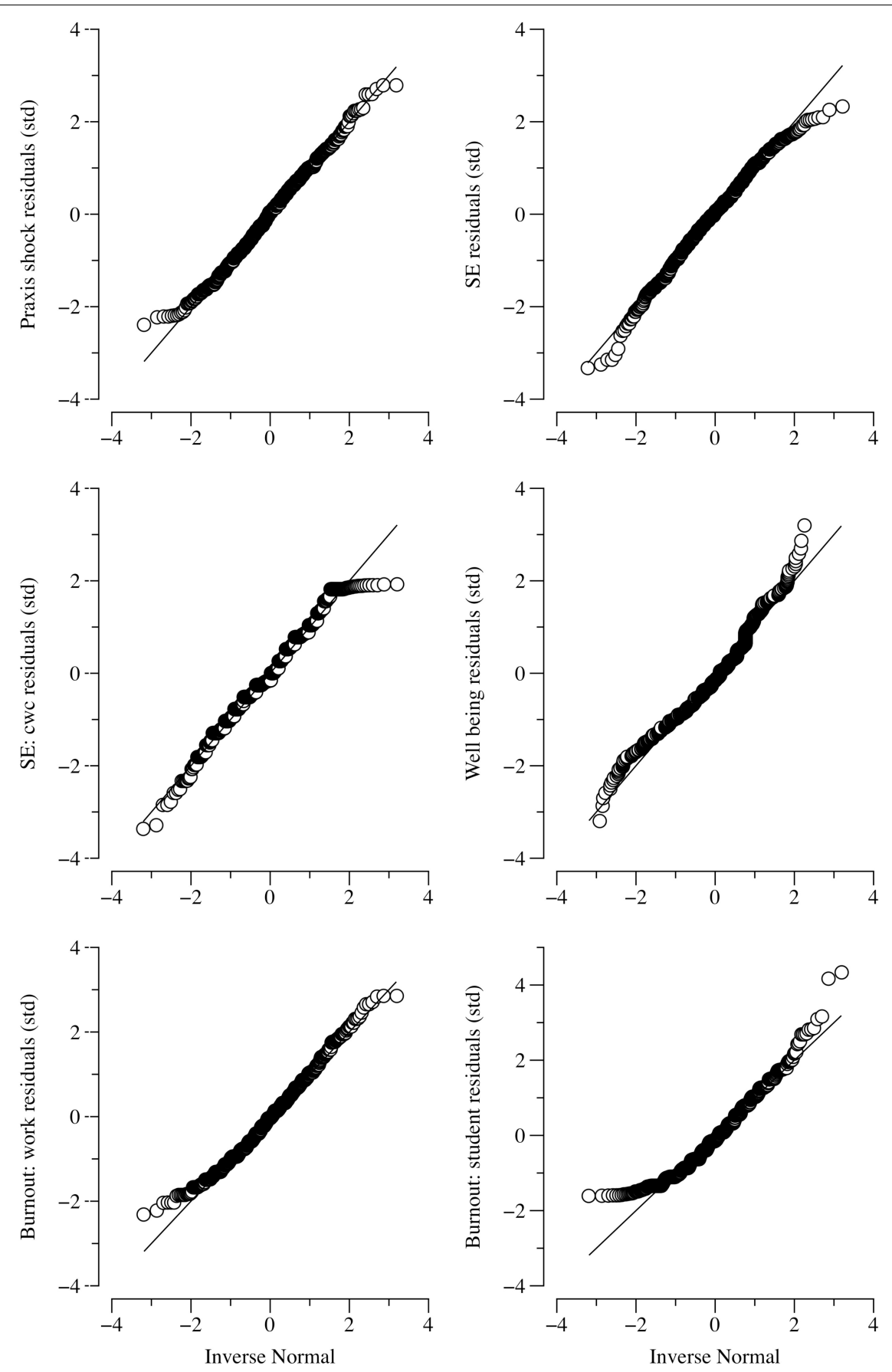

FIGURE 2 | Quantile-quantile plots showing normality fits for all linear models.

\section{CONCLUSION}

This paper explored the complexities that lie within the relationships between self-reported levels of self-efficacy, praxis shock, burnout, and well-being for music teachers, and time in a career. This study provides evidence that levels of burnout, well-being, self-efficacy, and most importantly praxis shock, are influenced by the number of years that teachers have been teaching. Additionally, levels of praxis shock predict levels of burnout, well-being and self-efficacy.

Our findings demonstrate that there are distinct challenges in the early career and late career periods of a music teacher's working life. Day and Gu (2007) found that teachers who were 24-30 years post-graduation found themselves in a phase where they have to adjust to changes associated with "deteriorating pupil behaviors, adverse personal events, resentment at 'being forced to 
jump through hoops by a constant stream of new initiatives, and career stagnation". Teachers in this life phase are at greater risk of being less effective, largely due to the likelihood of experiencing "extreme professional life phase scenarios (p. 437). It is highly likely that the experiences both early in the career and later in the career are associated with attrition from the profession. At the very least, providers of pre-service teacher education and inservice teacher education would be well advised to consider the impact of praxis shock across the career in terms of burnout and well-being.

As praxis shock is largely about the dissonance between expectations and the realities of working life, it is likely that awareness of the trends identified in this study will enhance awareness of the support necessary for teachers across the career - where praxis shock appears to be evident even later into the career. Targeted career-stage support needs to be developed for teachers, to assist them in navigating difficult periods successfully. Perhaps the development of a "proactive praxis" strategy in in-service teacher support will enable the pre-empting of the likelihood of praxis shock. For example, $\mathrm{Gu}$ and Day's (2007) work examining teacher identities and life stages suggest that in-service support focussing on ways to address external policy initiatives, helped more experienced teachers maintain enthusiasm and commitment to teaching during periods of praxis shock. Another suggestion is the use of strategies from positive psychology - qualitative findings with early-career teachers suggest that resilience developed through a positive psychology approach is indicated as protective against the negative impacts of praxis shock (Ballantyne and Zhukov, 2017). It is likely that support designed for experienced teachers might initially address similar issues to those addressed early in the career, but further research is warranted to investigate the nature of later-career praxis shock, in order for a nuanced support approach to be developed.

Support strategies for pre-service teachers are equally important. Demystifying the teaching experience and actively encouraging pre-service teachers to engage critically with their teaching experiences is likely to be key to negating praxis shock. Support strategies might involve addressing well-being and selfefficacy explicitly during university education, so that prior to embarking on their career, pre-service teachers might be better equipped to navigate successfully through the difficult first five years, minimizing their likelihood of experiencing burnout.

As identified by Hong (2010), emotional burnout is critical in influencing success in the profession. The current study goes further by showing that reported praxis shock impacts on burnout. It should be noted that the findings by Fiorilli et al. (2017) indicate that teachers who may be undergoing the experience of praxis shock may interpret students' actions in a more negative way - this may be associated with student-related burnout.

The links found between praxis shock and self-efficacy echo the arguments put forward by Gibbs (2001), who claimed that self-efficacy is the key to managing anxiety and stress associated with praxis shock. Gibbs emphasized that strategies specifically aimed at supporting teachers should result in enhanced self-efficacy.
This study also raises questions about other similar professions where burnout has been identified at the beginning of the career (for example, in health professions, psychology, law enforcement, legal, and even academia). Indeed, as this paper looked exclusively at teachers identifying as music specialists, it would be interesting to see to what extent this trend is evident in teachers with other specializations, and even generalist primary teachers. The praxis shock questionnaire items developed for the current study provide a useful tool for the investigation of other professions.

Our data do not reveal whether some of the issues have to do with time in the teaching role or perhaps changes to the nature of teaching over time. To address this question, a longitudinal study is required. The changing nature of schools, teaching methods, accountability demands, and technology infiltrating the classroom may damage self-efficacy for teachers who have been in the industry for many years $(>5)$, and this may be the reason for persistent praxis shock in the later parts of the career. In addition, the varied contexts from which the respondents came (including across different countries), means that contextualization in terms of common experiences is not possible. Indeed, even if the data were limited to one country, common experiences are unlikely to be evident; even within Australia, the experiences of music teachers vary from school to school. Future analyses of the longitudinal data (the 2nd and 3rd phases of questionnaire analysis with the same respondents) are likely to shed more light on how the experience of praxis shock and burnout, as well as teachers' well-being and self-efficacy change over time.

It should also be noted that this data was collected from teachers who were currently teaching, and it therefore, does not include those teachers who had left the profession. Hong (2010) found that those teachers who did burn out and consequently left teaching were more likely to admit to being extremely stressed about the work itself (work burnout in this study). Also evident in Hong's research is the impact of student-related stress (p. 1537). Although teachers who remained in the profession reported less emotional burnout, it did not seem to affect their professional identities and lives (Hong, 2010).

The apparent occurrence of praxis shock throughout the career is likely to have an impact on the development of sustainable and productive professional identities. In the case of music teachers, it has been argued that how music teachers think about themselves as musicians and as educators, and how proficient they are in these areas (their self-efficacy), is demonstrably associated with their identities (Hargreaves et al., 2007; Ballantyne and Grootenboer, 2012; Ballantyne et al., 2012; Ballantyne and Zhukov, 2017). Professional identity development has consistently been related to self-efficacy (Hargreaves et al., 2007) and teacher identity arguably has a prominent role to play in teacher praxis (Beijaard et al., 2004; Sachs, 2005; Diez and Raths, 2007). More needs to be known about how professional contexts, praxis shock and identity interrelate, and how these factors over the career play a role in the development of confidence and effectiveness as a professional. Investigating the nuances in these interrelationships is an area for future research and one that will hopefully emerge from the analysis of the fuller data from this project. 


\section{DATA AVAILABILITY STATEMENT}

The datasets generated for this study will not be made publicly available as it was a condition of ethical approval that only the authors are able to access the data.

\section{ETHICS STATEMENT}

The studies involving human participants were reviewed and approved by the University of Queensland Ethics Committee. Participants read a full information statement about the study, and gave their consent to participate prior to beginning the questionnaire. The participants provided their written informed consent to participate in this study.

\section{REFERENCES}

Ballantyne, J. (2005). "Identities of music teachers: implications for teacher education," in Proceedings of the Teacher Education: Local and Global: Australian Teacher Education Association Conference, ed. M. Cooper (Gold Coast, QLD: Australian Teacher Education Association), 39-44.

Ballantyne, J. (2007). Documenting praxis shock in early-career australian music teachers: the impact of pre-service teacher education. Int. J. Music Educ. 25, 181-191. doi: 10.1177/0255761407083573

Ballantyne, J., and Grootenboer, P. (2012). Exploring relationships between teacher identities and disciplinarity. Int. J. Music Educ. 30, 368-381. doi: 10.1177/ 0255761412459165

Ballantyne, J., Harrison, S., Barrett, M., and Temmerman, N. (2009). Bridging Gaps in Music Teacher Education: Developing Exemplary Practice Models Using Peer Collaboration. Sydney, NSW: Australian Learning and Teaching Council.

Ballantyne, J., Kerchner, J., and Aróstegui, J. (2012). Developing music teacher identities: an international multi-site study. Int. J. Music Educ. 30, 211-226. doi: 10.1177/0255761411433720

Ballantyne, J., and Zhukov, K. (2017). A good news story: early-career music teachers' accounts of their "flourishing" professional identities. Teach. Teach. Educ. 68, 241-251. doi: 10.1016/j.tate.2017.08.009

Bandura, A. (2006). Toward a psychology of human agency. Perspect. Psychol. Sci. 1, 164-180. doi: 10.1111/j.1745-6916.2006.00011.x

Beauchamp, C., and Thomas, L. (2009). Understanding teacher identity: an overview of issues in the literature and implications for teacher education. Cambridge J. Educ. 39, 175-189. doi: 10.1080/03057640902902252

Beijaard, D., Meijer, P., and Verloop, N. (2004). Reconsidering research on teachers' professional identity. Teach. Teac. Educ. 20, 107-128. doi: 10.1016/j.tate.2003. 07.001

Betoret, F. (2006). Stressors, self-efficacy, coping resources, and burnout among secondary school teachers in Spain. Educ. Psychol. 26, 519-539. doi: 10.1080/ 01443410500342492

Buonomo, I., Fatigante, M., and Fiorilli, C. (2017). Teachers' burnout profile: risk and protective factors. Open Psychol. J. 10, 190-201. doi: 10.13075/ijomeh.1896. 00238

Conway, C. (2012). Ten years later, experienced teacher reflections on "beginning music teacher perceptions of district-sponsored induction programs" (2001). Bull. Council Res. Music Educ. 193, 63-76.

Day, C., and Gu, Q. (2007). Variations in the conditions for teachers' professional learning and development: sustaining commitment and effectiveness over a career. Oxf. Rev. Educ. 33, 423-443. doi: 10.1080/0305498070145 0746

Day, C., and Kington, A. (2008). Identity, well-being and effectiveness: the emotional contexts of teaching. Pedagogy Cult. Soc. 16, 7-23. doi: 10.1080/ 14681360701877743

Diez, M. E., and Raths, J. D. (2007). Dispositions in Teacher Education. Charlotte, NC: Information Age Pub.

\section{AUTHOR CONTRIBUTIONS}

JB led all aspects of this project and writing of the manuscript. JR assisted with the statistical analysis.

\section{ACKNOWLEDGMENTS}

The authors gratefully acknowledge the support for this project provided by the University of Queensland Foundation Research Excellence Awards. Many thanks also go to the research assistants who worked on the project - Michael Ireland, Tammie OlmMadden, Claire Petherick, Nigel Bond, Rachael Dwyer, and Katie Zhukov. For this paper, the support provided by Michael Ireland for the initial work establishing the scales for the questionnaire was particularly appreciated.

Fernet, C., Guay, F., Senécal, C., and Austin, S. (2012). Predicting intraindividual changes in teacher burnout: the role of perceived school environment and motivational factors. Teach. Teach. Educ. 28, 514-525. doi: 10.1016/j.tate.2011. 11.013

Fiorilli, C., Pepe, A., Buonomo, I., and Albanese, O. (2017). At-risk teachers: the association between burnout levels and emotional appraisal processes. Open Psychol. J. 10, 129-139.

Flores, M., and Day, C. (2006). Contexts which shape and reshape new teachers' identities: a multi-perspective study. Teach. Teach. Educ. 22, 219-232. doi: 10.1016/j.tate.2005.09.002

Gibbs, C. (2001). Explaining effective teaching: self-efficacy and thought control of action. J. Educ. Enquiry 4, 1-14.

$\mathrm{Gu}, \quad$ Q., and Day, C. (2007). Teachers resilience: a necessary condition for effectiveness. Teach. Teach. Educ. 23, 1302-1316. doi: 10.1016/j.tate.2006.06.006

Hargreaves, D. J., Purves, R. M., Welch, G. F., and Marshall, N. A. (2007). Developing identities and attitudes in musicians and classroom music teachers. Br. J. Educ. Psychol. 77, 665-682. doi: 10.1348/000709906x154676

Hong, J. Y. (2010). Pre-service and beginning teachers' professional identity and its relation to dropping out of the profession. Teach. Teach. Educ. 26, 1530-1543. doi: 10.1016/j.tate.2010.06.003

Hultell, D., Melin, B., and Gustavsson, J. P. (2013). Getting personal with teacher burnout: a longitudinal study on the development of burnout using a personbased approach. Teach. Teach. Educ. 32, 75-86.

Kelchtermans, G., and Ballet, K. (2002). The micropolitics of teacher induction. A narrative-biographical study on teacher socialisation. Teach. Teach. Educ. 18, 105-120. doi: 10.1016/s0742-051x(01)00053-1

Kristensen, T., Borritz, M., Villadsen, E., and Christensen, K. (2005). The copenhagen burnout inventory: a new tool for the assessment of burnout. Work Stress 19, 192-207. doi: 10.1080/02678370500297720

Krueger, P. J. (2001). Reflections of beginning music teachers: the concerns of new teachers frequently overlap, and being aware of these issues may benefit veteran teachers who want to help. Music Educ. J. 88, 51-54. doi: 10.2307/3399759

Legette, R. M. (2013). Perceptions of early-career school music teachers regarding their preservice preparation. Update 32, 12-17. doi: 10.1177/ 8755123313502342

Lindqvist, P., Nordänger, U., and Carlsson, R. (2014). Teacher attrition the first five years - a multifaced image. Teach. Teach. Educ. 40, 94-103. doi: 10.1016/j.tate. 2014.02.005

Litano, M., and Major, D. (2016). Facilitating a whole-life approach to career development: the role of organizational leadership. J. Career Dev. 43, 52-65. doi: 10.1177/0894845315569303

Mark, D. (1998). The music teachers' dilemma - musician or teacher? Int. J. Music Educ. 32, 3-23. doi: 10.1177/02557614980320 0102

Parliament of Australia Media Release (2019). Parliament Learning From Teachers. Available at: https://www.aph.gov.au/Parliamentary_Business/Committees/ 
House/Employment_Education_and_Training/TeachingProfession/Media_ Releases (accessed November 11, 2019).

Pillen, M. T., den Brok, P. J., and Beijaard, D. (2013). Profiles and change in beginning teachers' professional identity tensions. Teach. Teach. Educ. 34, 86-97. doi: $10.1016 /$ j.tate.2013.04.003

Sachs, J. (2005). "Teacher education and the development of professional identity: learning to be a teacher," in Connecting Policy and Practice: Challenges for Teaching and Learning in Schools and Universities, eds P. Denicolo and M. Kompf (Oxford: Routledge), 5-21.

Schaefer, L. (2013). Beginning teacher attrition: a question of identity making and identity shifting. Teach. Teach. 19, 260-274. doi: 10.1080/13540602.2012. 754159

Scheib, J. (2006). Policy implications for teacher retention: meeting the needs of the dual identities of arts educators. Arts Educ. Policy Rev. 107, 5-10. doi: 10.3200/aepr.107.6.5-10

Shaw, J. (2016). Alleviating praxis shock: induction policy and programming for urban music educators. Arts Educ. Policy Rev. 119, 1-11. doi: 10.1080/10632913. 2016.1185655

Skaalvik, E., and Skaalvik, S. (2007). Dimensions of teacher self-efficacy and relations with strain factors, perceived collective teacher efficacy, and teacher burnout. J. Educ. Psychol. 99, 611-625. doi: 10.1037/0022-0663.99.3.611

Skaalvik, E., and Skaalvik, S. (2010). Teacher self-efficacy and teacher burnout: a study of relations. Teach. Teach. Educ. 26, 1059-1069. doi: 10.1016/j.tate.2009. 11.001

Skaalvik, E., and Skaalvik, S. (2014). Teacher self-efficacy and perceived autonomy: relations with teacher engagement, job satisfaction, and emotional exhaustion. Psychol. Rep. 114, 68-77. doi: 10.2466/14.02.pr0.114k14w0
Smagorinsky, P., Cook, L. S., Moore, C., Jackson, A. Y., and Fry, P. G. (2004). Tensions in learning to teach: accommodation and the development of a teaching identity. J. Teach. Educ. 55, 8-24. doi: 10.1177/0022487103260067

Stokking, K., Leenders, F., De Jong, J., and Van Tartwijk, J. (2003). From student to teacher: reducing practice shock and early dropout in the teaching profession. Eur. J. Teach. Educ. 26, 329-350. doi: 10.1080/0261976032000128175

Tschannen-Moran, M., and Woolfolk-Hoy, A. (2001). Teacher efficacy: capturing an elusive concept. Teach. Teach. Educ. 17, 783-805. doi: 10.1016/s0742051x(01)00036-1

World Health Organisation-Five Well-Being Index, (1998). World Health Organisation-Five Well-Being Index. Available at http://www.who-5.org (accessed April 17, 2012).

Zee, M., and Koomen, H. (2016). Teacher self-efficacy and its effects on classroom processes, student academic adjustment, and teacher well-being: a synthesis of 40 years of research. Rev. Educ. Res. 84, 981-1015. doi: 10.3102/ 0034654315626801

Conflict of Interest: The authors declare that the research was conducted in the absence of any commercial or financial relationships that could be construed as a potential conflict of interest.

Copyright (๑) 2020 Ballantyne and Retell. This is an open-access article distributed under the terms of the Creative Commons Attribution License (CC BY). The use, distribution or reproduction in other forums is permitted, provided the original author(s) and the copyright owner(s) are credited and that the original publication in this journal is cited, in accordance with accepted academic practice. No use, distribution or reproduction is permitted which does not comply with these terms. 
APPENDIX A | Questionnaire items.

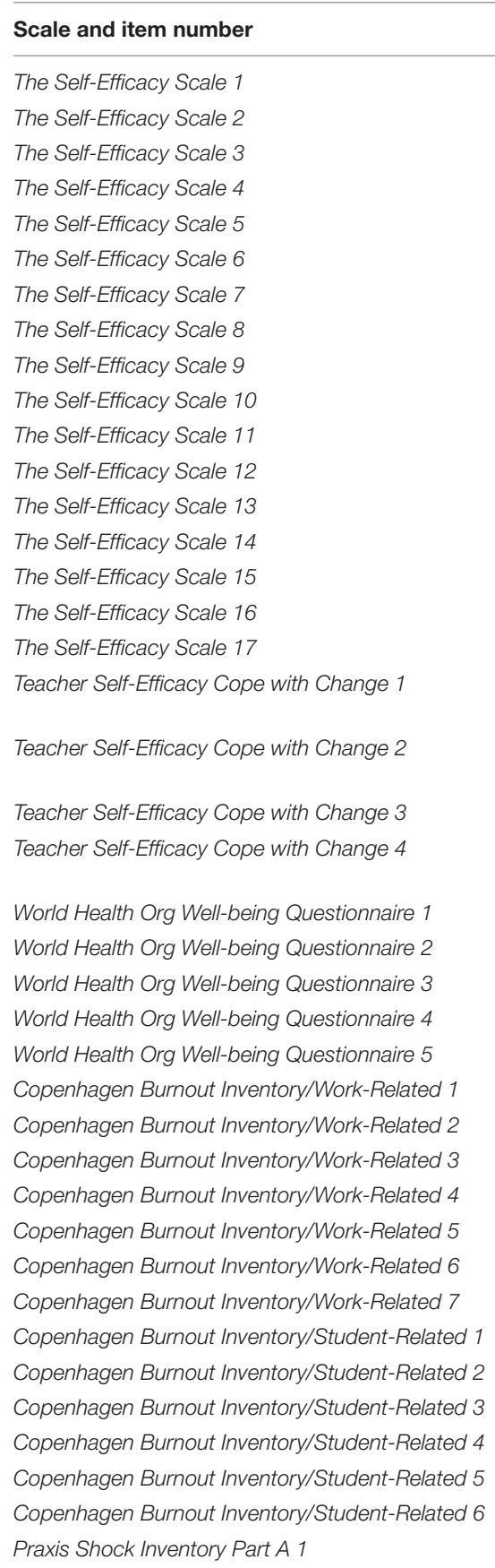

Praxis Shock Inventory Part A 2

Praxis Shock Inventory Part A 3

Praxis Shock Inventory Part A 4

Praxis Shock Inventory Part A 5

Praxis Shock Inventory Part A 6

\section{Item text}

When I plan lessons, I am certain I can make them work

One of my problems is that I cannot get down to lesson preparation when I should

If a lesson goes poorly the first time, I try again until it works better

When I set important goals for my teaching, I rarely achieve them

I give up on things before completing them

I avoid facing difficult situations in my teaching

If something on the syllabus appears complicated, I will not bother trying to teach it

When I have something unpleasant to do, I stick to it until I finish it

When I decide to do something, I go right to work on it

When trying something new in my teaching, I soon give up if I am not initially successful

If something unexpected happens during a lesson, I do not handle it well

I avoid trying something new in my teaching if it looks too difficult for me

Failure just makes me try harder

I feel insecure about my teaching

I am a self-reliant learner

I give up easily

I do not seem capable of dealing with most problems that come up in my teaching activities

How certain are you that you can successfully use any instructional method that the school decides to use?

How certain are you that you can manage instruction regardless of how it is organized (group, composition, mixed age groups, etc.)?

How certain are you that you can manage instruction even if the curriculum is changed?

How certain are you that you can teach well even if you are told to use instructional methods that would not be your choice?

Over the last two weeks I have felt cheerful and in good spirits

Over the last two weeks I have felt calm and relaxed

Over the last two weeks I have felt active and vigorous

Over the last two weeks I woke up feeling fresh and rested

Over the last two weeks my daily life has been filled with things that interest me

Is teaching emotionally exhausting?

Do you feel burnt out because of teaching?

Does teaching frustrate you?

Do you feel worn out at the end of the working day?

Are you exhausted in the morning at the thought of another day at work?

Do you feel that every working hour is tiring for you?

Do you have enough energy for family and friends during leisure time?

Do you find it hard to work with students?

Do you find it frustrating to work with students?

Does it drain your energy to work with students?

Do you feel that you give more than you get back when you work with students?

Are you tired of working with students?

Do you sometimes wonder how long you will be able to continue working with students?

When you first began teaching (work), were you surprised or even shocked with any aspects of the workload and expectations placed on you?

When you first began teaching (your job), were you surprised or even shocked with any aspects of the school culture?

When you first began teaching (your job), were you surprised or even shocked with any aspects of the time and energy required to meet the demands of your job?

When you first began teaching (your job), were you surprised or even shocked with any aspects of the level of support you received?

When you first began teaching (your job), were you surprised or even shocked with any aspects of the attitudes or behavior of students?

When you first began teaching (your job), were you surprised or even shocked with any aspects of your relationship with other staff? 
APPENDIX A | Continued

\section{Scale and item number}

Praxis Shock Inventory Part B 1

Praxis Shock Inventory Part B 2

Praxis Shock Inventory Part B 3

Praxis Shock Inventory Part B 4

Praxis Shock Inventory Part B 5

Praxis Shock Inventory Part B 6

Praxis Shock Inventory Part B 7

Praxis Shock Inventory Part B 8

Praxis Shock Inventory Part B 9

\section{Item text}

How accurate were your pre-service ideas about day-to-day life as a teacher?

To what extent do the pressures of the job impact on your ability to be the teacher you would hope to be?

Were any of your pre-service beliefs and ideas about teaching inaccurate?

Are other teachers and staff as supportive as you thought they would be?

Has daily life as a teacher challenged any of the pre-service beliefs and ideas about teaching you held about life working as a teacher?

How realistic were the pre-service expectations you held about life as a teacher?

Do you think you began your career with a good grasp of what school life is like for a teacher? How closely do your preconceptions about being a teacher fit with the realities of teaching?

Have you experienced any clash between the vision of teaching you had before beginning and the realities of the job? 